\title{
Video reviews
}

\author{
Tape details \\ Ratings \\ *** highly recommended \\ ** recomended \\ worth looking at \\ 0 no rating
}

\section{Helping people grieve - the role of the health worker}

Grieving is a normal human reaction; it demonstrates the importance one person has for another. Relationships give shape to human life, providing recognition, personal and biological fulfilment, the opportunity to love and be loved, the creation of networks and shared interest, and the expression of social concern. Relationships can also be the source of frustration, limitation and inhibition. A lack of relationships engenders disturbing feelings of isolation, alienation and depersonalisation. Along with work, play and belief, relationships give purpose and meaning to human life. Grief is a common feeling but one that many struggle with alone and which may be slow to pass, leaving a legacy of unresolved, disabling reactions.

Helping people grieve is one of two videos produced by the Clinical Psychology Department of Gwent Community Health in partnership with Production House, a specialist in health care videos. Over 30 minutes, this well-produced tape introduces the viewer to the phenomenon of grief, the principles of management and some illustrations of practice. The target audience is the health care professional. The video is varied in style and pace which makes for easy viewing. Typically, a scene is set in an extract from a session, talked about by the clinician, the key practice points being then presented in tabular form and voiceover. Finally, either the therapy is taken a step further or the grieving person looks back on their experience. Examples of 'numbness' and unresolved grief are presented. The tone is sympathetic and positive.

This tape takes a person-centred and problemsolving approach. It would make a good base for small group discussion. It recognises that there is no set path for grief, an important practice point in itself. Beneficially, the recognition and expression of feelings is legitimised and the value of listening underlined. The process in which protest at the loss surfaces in anger with others is only mentioned in passing and should have been given greater prominence. Some losses are defin- ing events in particular lives and remain so. Understanding that and why is part of the helper's role.

\section{Tape details}

Production: Gwent Community Health Trust

Distribution: Production House, Gwent

Details: $\quad$ Video; 30 mins; 1995; £23.38

Rating ***

Audience: M, UG

MARK AVELINE, Psychotherapy Department, Mapperley Hospital, Nottingham

\section{Step by step: helping yourself to cope with panic}

This is a curate's egg of a video. The personal accounts of panic are realistic, clear and even inspiring, while the guidelines for graded exposure are thorough, concise and will prove valuable to the majority of viewers. These two strong points are, however, insufficient to commend the video.

The introduction to, and explanation of, panic is not very clear and the graphics are distractingly garish. This part of the video is saved only by the excellent accounts given by sufferers who are often clearer in formulating the model of panic than are the expert commentators.

The first of the panic management techniques, graded exposure, is very well explained. The technique is clearly outlined using a sound rationale, well defined steps and relevant, simple graphics. A sensitive case example makes the technique even more accessible to the viewer. Sadly, other coping strategles are less well conveyed.

As the narrators say, the most salient components of a panic attack are the physiological and cognitive aspects and these are the most poorly addressed. The rationale for introducing controlled breathing and relaxation to combat hyperventilation and muscular tension was obscure and the techniques muddled and possibly unhelpful. I would be unhappy about advocating the breathing technique used by the therapist in the video as the explanation was inadequate and the prescribed technique of breath holding combined with controlled breathing is unnecessary and can be distressing to clients with the 
common catastrophic fears of choking or suffocating. The cognitive management of worries was also poorly explained and the emphasised strategy was 'positive thinking' which is not necessarily the same as the rational thinking which is stressed by cognitive therapists. I fear that the message that a person can positively think her or himself out of a panic attack would set up many clients for disappointment.

Thus, I cannot recommend this video and have serious reservations about certain aspects of it.

\section{Tape details}

Production: Gwent Community Health Trust Distribution: Production House, PO Box 9 , Cwmbran, Gwent NP44 6YB

Details: $\quad$ Video; 55 mins; 1995; £23.38

Rating: $\quad 0$

Audience: $\quad \mathrm{M}, \mathrm{UG}$

HELEN KenNerley, Psychology Department, Warneford Hospital, Oxford

\section{False memories of child sexual abuse}

False memory syndrome, the induction in patients by the suggestions of their therapists of false memories of sexual abuse during childhood, is a real clinical problem which may have a devastating impact on patients and their families. Its ramifications pose a significant threat to psychological therapy services, and thereby to those patients who really did experience sexual abuse during childhood.

This short American video, although unfortunately acknowledging only in its conclusion that child sexual abuse is a real problem, addresses false memory syndrome without sensationalism or sentimentality. Drawing on the testimony of patients and the expertise of three prominent academics, the nature of the syndrome is elucidated as a product of the therapist's attribution of the patient's symptoms to childhood sexual abuse, then reinforced by the therapist's subsequent induction in the patient of false memories of abuse which never happened. The therapist may identify the abuser with conviction, and often will encourage the patient to confront the abuser personally or through legal action. In some cases the spectre of ritual satanic abuse has been seeded in the patient's mind, or her (the majority of victims are women) problems may be explained by the suggestion of multiple personalities.

Therapists who inculcate in their patients a belief that their problems are the result of childhood sexual abuse draw on the published evidence of the long-term psychiatric effects of abuse, but in a manner which imposes on the vulnerable patient the therapists' own suppositions and prejudices. In North America this development has led to increasingly widespread litigation against the practitioners of psychological therapies, and this now threatens the future of such treatment services.

The therapists' techniques for 'recovering' memories, particularly suggestion and guided imagery, are known to be capable of inducing false beliefs. Memories are constructed; they are not simply action-replays of earlier experiences, but complex psychological representations which incorporate elements dertved from other sources, including what is read, seen or heard. Despite the assertions of some therapists to the contrary. it is not possible to distinguish genuine from false memories. Whatever their profession or theoretical model, therapists work with patients who disclose spontaneously their memories of sexual abuse. The art of psychotherapy is to accept and address the patient's narrative account of their experience, but without making suggestions about its cause or embellishing the patient's memory in any way, particularly when the patient is looking desperately for answers to dispel anxiety and uncertainty.

This video was produced by the False Memory Society Foundation, which has researched the subject and aims to support both accused families and those patients who retract their accusations in an attempt at reconciliation. The video is useful as a means of raising awareness and promoting discussion of false memory syndrome among mental health practitioners. More attention might have been devoted usefully to the psychology of memory, and to a more detailed review of the means by which misguided or malevolent therapists may induce or elaborate false memories. Unfortunately, though perhaps wisely, the video does not even begin to examine the nature of repression. A more serious omission, which limits the value of the video for mental health practitioners, is the absence of any systematic examination of the implications for clinical practice.

\section{Tape details}

Production: False Memory Syndrome Foundation, Philadelphia, Pennsylvania

Distributor: British False Memory Society, Belcombe Croft, Bradford on Avon.

Wiltshire BA15 1NA

Details: Video; 15 mins; $£ 10$

Rating: *

MIKE HOBBS, Psychotherapy

Warneford Hospital, Oxford 